\title{
FIRST RECORDS OF THE GENUS Eugalta Cameron, 1899 (Hymenoptera: Ichneumonidae: Poemeniinae) FROM VIETNAM
}

\author{
Pham Thi Nhi ${ }^{1}$, Khuat Dang Long ${ }^{1}$, Cornelis van Achterberg ${ }^{2}$ \\ ${ }^{1}$ Institute of Ecology and Biological Resources, VAST \\ ${ }^{2}$ Department of Terrestrial Zoology, Naturalis Biodiversity Center, Postbus 9517, 2300 RA Leiden, \\ The Netherlands; Key Laboratory of Resource Biology and Biotechnology in Western China \\ (Northwest University), Ministry of Education; School of Life Sciences, Northwest University, 229 \\ North Taibai Road, Xi'an, Shaanxi 710069, China
}

\begin{abstract}
S: The genus Eugalta Cameron, 1899 (Ichneumonidae: Poemeniinae) is reported for the first time from Vietnam after studying the Ichneumonidae collections recently assembled at the Institute of Ecology and Biological Resources (Ha Noi) and the Naturalis Biodiversity Center(Leiden). A key to seven species of Eugaltais compiled. Eugalta punctulata yamuna (Gupta, 1980), is a junior synonym of the nominate subspecies, E. punctulata punctulata Cameron, 1899, syn. nov.
\end{abstract}

Keywords: New record, parasitoid, taxonomy.

Citation: Pham Thi Nhi, Khuat Dang Long, van Achterberg C., 2017. First records of the genus Eugalta Cameron, 1899 (Hymenoptera: Ichneumonidae: Poemeniinae) from Vietnam. Tap chi Sinh hoc, 39(4): 467473. DOI: 10.15625/0866-7160/v39n4.11242.

*Corresponding author: ptnhi2@yahoo.com

Received 5 December 2016, accepted 12 August 2017

\section{INTRODUCTION}

When Cameron (1899) described the genus Eugalta, he recognized two groups on the basis of presence/absence of an areolet in the fore wing. Almost simultaneously, Kriechbaumer (1899) described Achorocephalus to include his new species, A. cinctipes. Ashmead (1990) named a new genus, Pseudeugalta, for reception of the species possessing the areolet, but it was later synonymized with Eugalta by Morley (1915). Townes (1969) synonymized both Achorocephalus and Pseudeugalta with Eugalta. However, Gupta (1969) showed some more characteristics along with the presence/absence of an areolet and retained Pseudeugaltaas valid genus. This division was used until Gupta (1980). The genus Achorocephalus was used again by Gupta (1985) and this author synonymized Pseudeugalta under this genus. Wahl \& Gauld (1998) used cladistics analysis of 91 characters to confirm the valid status of Eugalta. Here we follow Wald \& Gauld (1998) and assign the specimens from Vietnam to the genus Eugalta.
Pseudogalta and Achorocephalus are used now as synonyms.

Eugalta is the most diverse genus of the tribe Poemeniini with 32 species currently known from the Australian, Palaearctic and Oriental regions ( $\mathrm{Yu}$ et al., 2012). They are believed to be parasitoids of wood-boring coleopterous larvae, such as Cerambycidae (Sheng \& Sun, 2010). In Vietnam, no species of Eugalta were documented so far. In this paper, this genus is reported for the first time from the country, with a key to Vietnamese species.

\section{MATERIALS AND METHODS}

All specimens were collected by Malaise traps, sweeping net and light traps from 2005 to 2017 and are deposited in the collections of the Institute of Ecology and Biological Resources (IEBR), Ha Noi, Vietnam and the Naturalis Biodiversity Center, Leiden, The Netherlands (RMNH). Other collections referred to in this paper are: Natural History Museum, London, UK (BMNH); Hungary, Budapest, Hungarian Natural History Museum (HNHM); University 
Museum of Natural History, Oxford, UK designation.

(OUMNH).

Diagnosis. Apex of mandible with single

Morphological terminology follows Gauld (1991). Photographs were taken with a Leica IC80HD camera attached to Leica M80 stereomicroscope.

Other abbreviations are used in this paper for National Park (NP), Nature Reserve (NR), and Vietnam National Museum of Nature (VNMN).

\section{TAXONOMIC RESULTS}

Eugalta Cameron, 1899

Eugalta Cameron, 1899: 135. Type species: Eugaltastrigosa Cameron, by subsequent broad, chisel-like tooth, clypeus small, flat, and subrectangular; inner margins eyes ventrally convergent; dorsal 0.5 of gena coarsely and strongly denticulate; eponia absent dorsad of pronotal collar; mesoscutumtriboled, without transverse rugae; notauli strongly developed; epicnemial carina absent; first metasomal tergite and its sternite clearly separated; hind tarsal claws symmetrical, the anterior one angled greater than or equal to $90^{\circ}$, simple, bearing a spatulate bristle at its base, the posterior one less strongly angled and with a flattened truncate lobe; median tooth of tarsal claw of fore and mid legs flattened and apically truncate.

\section{Key to Vietnamese species of Eugalta Cameron}

1. Fore wing with areolet open on outer side, vein 3rs-m completely absent (Fig. 1a); metasomal tergite 2 densely, coarsely punctate (fig. 1e).

- Fore wing with areolet closed, vein 3rs-m present, 1.3-1.4x as long as 2rs-m (Fig. 1b); metasomal tergite 2 more or less polished, with sparse punctures (fig. 1f)..

2. Scutellum, postscutellum and posterior part of propodeum yellow.

- Propodeum entirely black, scutellum and postscutellum wholly black or with yellow markings.

3. Middle lobe of mesoscutum with yellow spot laterally (fig. 1h); inner orbit yellow (fig. $1 \mathrm{~g})$.

- Mesoscutum and inner orbit entirely black, without any yellow markings.

4. Propleuronlargely yellow (Fig. 2e); submetapleural carina present on anterior 0.6 (fig. 2c); hind coxa with black stripe dorsally; first sternite extending beyond level of spiracle (fig. 1c)......

E. albitarsis

- Propleuronreddish brown (fig 2f); submetapleural carina strong, extending nearly all the length of metapleuron ventrally (fig. 2d); hind coxa largely black in posterior 0.6 ; first sternite extending to level of spiracle (fig. 1d).

E. longipes

5. Scutellum and postscutellum black; metapleural sculpture (fig. $1 \mathrm{k}$ ) weaker and different from that of propodeum (figs 1i).

E. pilosa

- Scutellum and postscutellum yellow; metapleural sculpture similar to that of propodeum.........6

6. Mesoscutum shiny, with scattered punctures (fig. 2a)...

E. nigricollis

- Mesoscutumsubpolished or mat, with denser punctures (fig. 2b).

E. punctulata

\section{Eugaltaalbitarsis Cameron, 1899}

Eugaltaalbitarsis Cameron, 1899. Mem.

Proc. Manchester Lit. Phil. Soc., 43(3):138. Holotype: + , India: Khasi Hills (OUMNH).
Material examined: Tuyen Quang Province, $\mathrm{Na}$ Hang, Thanh Tuong: $1 \overbrace{}^{\lambda} 1$ + (IEBR), N22 19'01" E105 24'02”, $162 \mathrm{~m}, 12.2016-$ 3.2017, Malaise trap, Khuat Dang Long leg. 
Distribution: Previously known from China, India and Myanmar (Yu et al., 2012).

Remarks: Two subspecies has been recognized: $E$. albitarsis albitarsis and E. albitarsis mysorensis. Of which the later was known only from southern India that differs from the former in colour of the inner orbit, propleuron, mesepimeron and legs. Vietnamese specimens belong to the nominate subspecies.

\section{Eugalta leucopus Townes, Townes \& Gupta, 1961}

Eugaltaleucopus Townes, Townes \& Gupta, 1961. Mem. Amer. Ent. Inst., 1: 80. Holotype: $\widehat{\jmath}$, India, Khasi Hills (OUMNH).
Material examined: Ninh Binh Province, Cuc Phuong NP: 1 ( (IEBR), 25.v.2005, light trap, Pham Hong Thai leg.; Thai Nguyen Province, Dai Tu, Cat Ne: 1 ㅇ (IEBR), 15.xii.2006, Malaise trap, Khuat Dang Long leg.; Tuyen Quang Province, Na Hang, Thanh Tuong: 1 ( (IEBR), N22 19'01" E105 24'02”, $162 \mathrm{~m}, 12.2016-3.2017$, Malaise trap, Khuat Dang Long leg.

Distribution: Previously known only from India (Yu et al., 2012).

Remarks: Vietnamese specimens have the first sternite extending beyond level of spiracle.
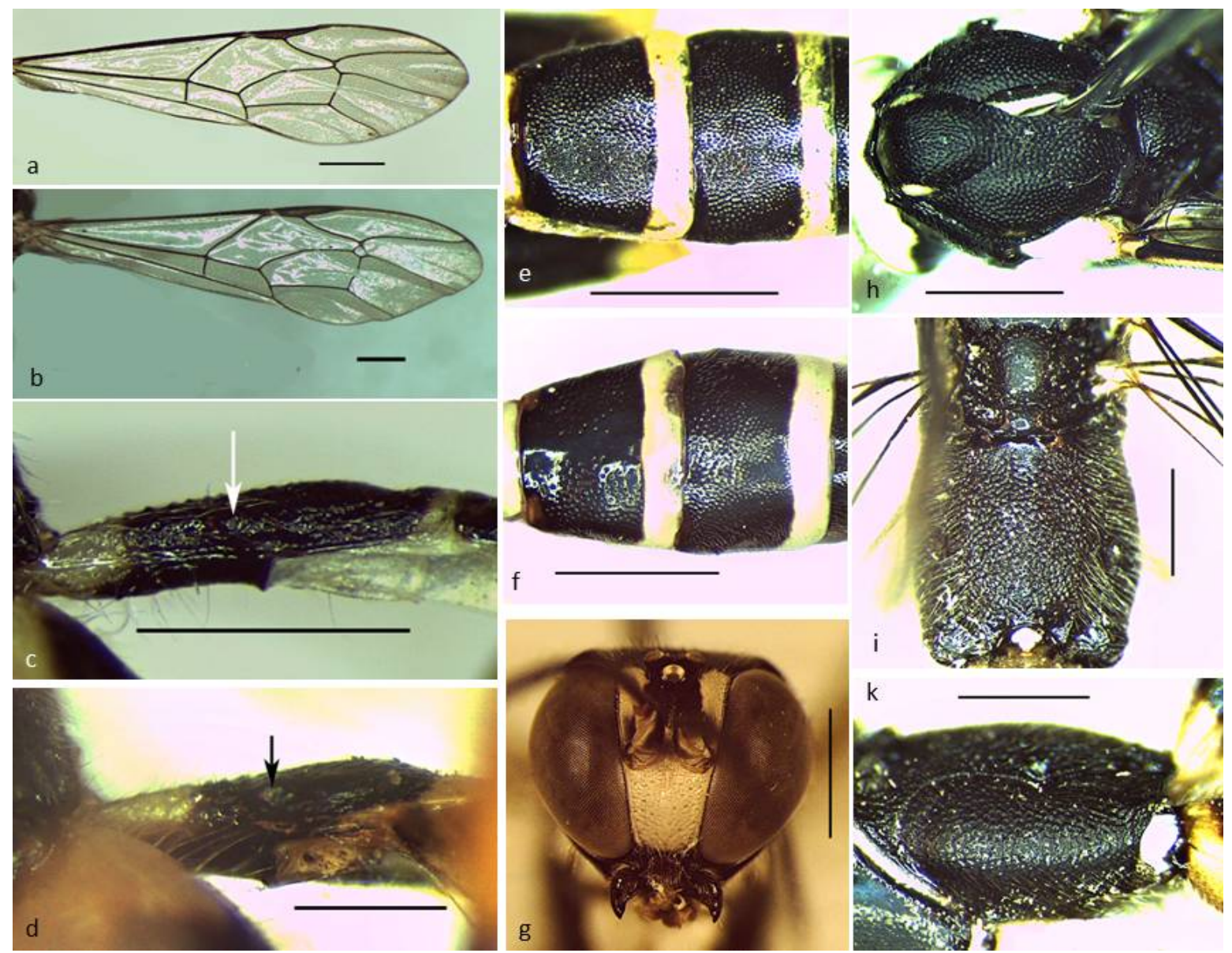

Figure 1. a: fore wing of E. albitarsis; b: fore wing of E. punctulata; c. lateral view of metasomal tergite 1 of E. albitarsis; d. lateral view of metasomal tergite 1 of $E$. longipes; e. dorsal view of tergites 2-3 of E. longipes; f. dorsal view of tergites 2-3 of E. punctulata; g. face of E. linearis; h. mesoscutum of E. linearis; i. dorsal view of propodeum of E. pilosa; i. metapleuron of E. pilosa. (scale bar: $1 \mathrm{~mm}$ ). 


\section{Eugalta linearis Morley, 1913}

Eugalta linearis Morley, 1913. Fauna British India, Hymenoptera, 3(1): 73. Holotype: $\widehat{\jmath}$, India: Sikkim (BMNH).

Material examined: Hoa Binh Province, Mai Chau, Tan Son: 1q (IEBR), 1-5.iv.2009, Malaise trap, Khuat Dang Long leg.; Hoa Binh Province, Hang Kia-Pa Co NR: 19 (RMNH), N20 44'37' E104 56'20”, 1045 m, 9-23.x.2009, Malaise trap, C.v. Achterberg \& R. de Vriesleg.

Distribution: Previously known from China, India, Myanmar and the Philippines ( $\mathrm{Yu}$ et al., 2012).

Remarks: Three subspecies have been known: E. linearis linearis from China, India, Myanmar, E. linearis kumaoensis from India and E. linearis philippina from the Philippines. Vietnamese specimens belong to the nominate subspecies that can be distinguished from the others by broadly yellow inner orbit, yellow lateral spot of mesoscutal median lobe and yellow markings on scutellum and postscutellum.

\section{Eugalta longipes (Cameron, 1906)}

Bathymeris longipes Cameron, 1906. Entomologist, 39: 51. Holotype: + , India: Sikkim (BMNH).

Material examined: Phu Tho Province, Xuan Son NP: 19 (IEBR), 7.v.2005, hand net, Pham Thi Nhi leg.

Distribution: Previously known from India, Myanmar and Thailand (Yu et al., 2012).

\section{Eugalta nigricollis Cameron, 1899}

Eugalta nigricollis Cameron, 1899. Mem. Proc. Manchester Lit. Phil. Soc., 43(3): 141. Holotype: $\widehat{\jmath}$, India: Khasi Hills (OUMNH).

Material examined: DakLak Province, Eo So NR: $1 \delta^{\Uparrow}$ (IEBR), $12^{\circ} 55.93^{\prime} \mathrm{N} 108^{\circ} 37.946$ 'E , 310 m, 27.7.2008, Malaise trap, Ngo Thu Hien leg.; Binh Thuan Province, Bac Binh, Phan Son: 10َ(IEBR), N 21 07'28" E126 84'71”, 212 m, 5-15.viii.2011, Malaise trap, Nguyen Quang Truong leg.; Vinh Phuc Province, Phuc Yen, Ngoc Thanh: 19 (IEBR), 1-30.xi.2014, Malaise trap, Pham Thi Nhi leg.; TuyenQuang Province, $\mathrm{Na}$ Hang, Thanh Tuong, N22 19'01" E105 24'02", 162 m, Malaise trap, Khuat Dang

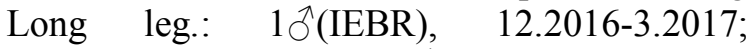
1 (IEBR), 5.ii.2017; 2今(IEBR), 5.iii.2017; Nghe An Province, Pu Mat NP: $2{ }^{\lambda}$ (IEBR), N18 57'22.8” E 104'41'5.3”, 187 m, 47.v.2017; 1 1 $\quad$ (IEBR), N 18 57'20.7” $\mathrm{E}$ $104^{\circ} 41^{\prime 1} .4$ ", $192 \mathrm{~m}, 8$-12.v.2017, hand net, Hoang Vu Tru leg.

Distribution: Previously known from Bangladesh, China, India, Indonesia, Laos, Malaysia and Myanmar (Yu et al., 2012).

Remarks: Currently, four subspecies are known: $E$. nigricollis nigricollis, $E$. nigricollisconspicua, E. nigricollis maculiseutis and E. nigricollis malayana. They can be recognized by the colour of legs (especially hind leg), inner orbit and propleuron. Eugalta nigricollis malayana from Malaysia is characterized by its entirely black hind femur whereas the three other subspecies have reddish yellow and black banded femur. Vietnamese specimens show large variation of black marking of their hind femur, even though they were collected from the same locality. For instance, one male specimen collected from Tuyen Quang Province on 5.iii.2017 has anterior 0.7 of femur reddish yellow and posterior 0.3 black, in contrast to three other specimens collected from this site having only anterior 0.2 reddish yellow and posterior 0.8 offemur black. The same is present in specimens collected in $\mathrm{Pu}$ Mat NP. One male specimen collected 4-7.v.2017 has anterior 0.1 of femur reddish yellow and posterior 0.9 black, whereas, two other specimens have anterior 0.7 of femur reddish yellow and posterior 0.3 black. One specimen collected from Eo So NR has yellowish inner orbits similar to E. nigricollis conspicua, however the colour of the hind femur is different. The status of these subspecies needs to be reconsidered since it dependstoo much on colour pattern, however we have not examined these subspecies to make any confirmation. 

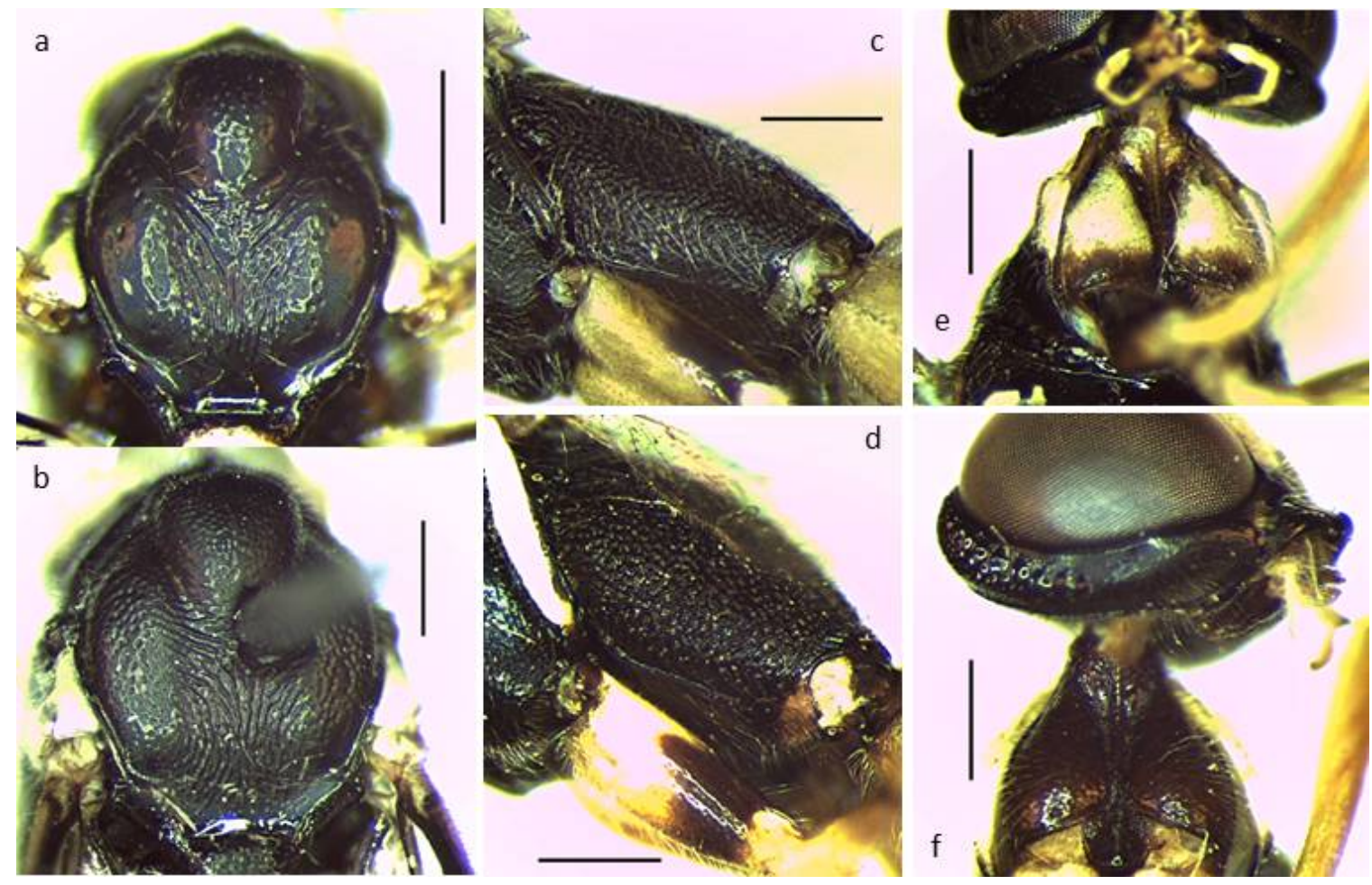

Figure 2. a: mesoscutum of E. nigricollis; b: mesoscutum of E. punctulata; c. metapleuron of $E$. albitarsis; d. metapleuron of $E$. longipes; e.propleuron of $E$. albitarsis; f. propleuronof E. longipes. (scale bar $0.5 \mathrm{~mm}$ ).

\section{Eugalta pilosa (Szépligeti, 1914)}

Achorocephalus pilosus Szépligeti 1914. Ann. Mus. Natl. Hungarici, 12:423. Holotype: + , Taiwan: [Kosempo] (HNHM).

Material examined: 1 ( $(\mathrm{IEBR})$, Phu Tho Province, Xuan Son National Park, 1015.ix.2009, Malaise trap, Khuat Dang Long leg.

Distribution: Previously known from China, Japan and Taiwan (Yu et al., 2012).

\section{Eugalta punctulata Cameron, 1899}

Eugalta punctulata Cameron, 1899. Mem. Proc. Manchester Lit. Phil. Soc. , 43(3): 142. Holotype: + , India: Khasi Hills (OUMNH).

Material examined: Vinh Phuc Province, Phuc Yen, Ngoc Thanh: 1q(IEBR), 8.vi.2005, hand net; $1 \sigma^{\top}$ (IEBR), 1-30.iv.2015, Malaise trap, Pham Thi Nhi leg.; Dong Nai Province, Cat Tien NP, 100 m: $1 \widehat{\jmath}$ (RMNH), 3-6.x.2005, near headquarter, hand net, C. v. Achterberg leg.; 1q(RMNH), 19-25.iv.2007, Malaise trap, Mai Phu Quy \& Nguyen Thanh Manh leg.;
1 q(RMNH), 13-20.v.2007, Malaise trap, C. v. Achterberg \& R. de Vries leg.; Nghe An Province, Tuong Duong, Tam Quang: 1 (IEBR), 12.vii.2006, Nguyen Thi Thu Huong leg.; Dong Nai Province, Vinh Cuu, Ma Da: 19(IEBR), 9.iv.2009, hand net, Hoang Vu Tru leg.; Ha Tinh Province, Vu Quang NP: 10 (RMNH), near entrance, $97 \mathrm{~m}, \mathrm{~N} 18^{\circ} 19^{\prime} 43^{\prime \prime}$ E105 26'29”, 23.ix-5.x.2009, Malaise trap, C.v. Achterberg \& R. de Vries leg.; Da Nang Province, Da Nang islands: $1 \sigma^{\widehat{\lambda}}(\mathrm{RMNH}), 10 \mathrm{~m}$, N16 06'10'21 E108 15'54", 6-8.iv.2011 hand net, C.v. Achterberg leg.; Thua Thien-Hue Province, Bach Ma NP: 1 $\delta^{\lambda}(\mathrm{RMNH})$, near entrance, $75 \mathrm{~m}, \mathrm{~N} 16^{\circ} 15^{\prime} 01^{\prime \prime}$ E107 52'13”, 27.iii-12.iv.2011, Malaise trap, C. v. Achterberg leg.; Hoa Binh Province, Yen Thuy, Da Phuc: 1 (IEBR), 27.iv.2012, hand net, Dang Thi Hoa leg.; Tuyen Quang Province, Na Hang, Thanh Tuong: $1 \delta^{\Uparrow} 3$ ㅇ (IEBR), 12.2016-3.2017; 1ठ (IEBR), 5.ii.2017, N22 19'01" E105 24'02", 162 m, Malaise trap, Khuat Dang Long leg. 
Distribution: Previously known from Bangladesh, India and Myanmar (Yu et al., 2012).

Remarks: Two subspecies have been recognized: Eugalta punctulata punctulata and E. punctulatayamuna. Of which the later, recorded from India only, differs from the nominate subspecies by the colour pattern of the hind leg. One female specimen from Tuyen Quang Province belongs to the nomimate subspecies despite of its more extensive black marking on the hind femur posteriorly. Other Vietnamese specimens have the colour pattern of hind tibia similar to E. punctulata yamuna but the colour pattern of hind coxae resembles the former subspecies. As the differences between the two subspecies are obviously instable we here synonymise both two names.

\section{DISCUSSION}

On the basis of two recent collections of Vietnamese Ichneumonidae, seven species of the genus EugaltaCameron have been recorded. They are also the first representatives of the subfamily Poemeniinae known from the country. With seven recorded species, the species richness of this genus from Vietnam is lower than China (13 species) where including also the Palaearctic region, India (10 species) and Myanmar (8 species), but higher than other countries in the area such as the Philippines (6 species), Malaysia (5 species), Indonesia (4 species), Thailand and Laos (1 species, each) (Gupta, 1980; Wang \& Gupta, 1995; Sheng \& Sun, 2010; Yu et al., 2012). Eugalta species are very similar in general colour pattern. The key characters to identify Eugalta species include the presence or absence of anareoletin the fore wing, the sculpture of the mesoscutum, metapleuron and propodeum. Some other characters such as length of first sternite and tergite, shape of second tergite, and especially the colour of the legs are not stable. They are variable within populations or depend on gender. We therefore suspect that, when the Vietnamese fauna is studied in more detail, some species/subspecies will be synonymized since they were described as new on the basis of only some minor differences. However, a complete evaluation of the genus Eugalta is beyond the scope of this paper.

Acknowledgements: This research is funded by Vietnam National Foundation for Science and Technology Development (NAFOSTED) under grant number 106-NN.05-2015.04. We would like to thank Dr Gavin R. Broad (The Natural History Museum, UK) for providing scientific literatures. The first author acknowledges Prof. Mao-Ling Sheng, Prof. Shu-Ping Sun and Dr Tao Li for supporting her visit to General Station of Forest Pest Management, State Forestry Administration, Shenyang, Liaoning, China in late 2016. The visit of the first author to the Naturalis Biodiversity Center, Netherlands in 2014 was supported by the Martin Fellowship, with special thanks to Dr. Sandrine Ulenberg and Ms Frederique Bakker (RMNH) for access to the important collection of Ichneumonidae in Naturalis. Special thanks to colleagues from IEBR, VNMN, and Ngo Thu Hien, a Canadian entomologist, for providing valuable specimens. Some field equipment was supported by Idea Wild.

\section{REFERENCES}

Ashmead W. H., 1990. Classification of the Ichneumon flies, or the superfamily Ichneumonoidea. Proceedings of the United States National Museum, 23: 1-220.

Cameron P., 1899. Hymenoptera Orientalia, or Contributions to a knowledge of the Hymenoptera of the Oriental Zoological Region. Part VIII. The Hymenoptera of the Khasia Hills. Mem. \& Proc. Manchester Lit. Phil. Soc., 43: 1-220.

David B. W., Gauld I. D., 1998. The cladistics and higher classification of the Pimpliformes (Hymenoptera: Ichneumonidae). Systematic Entomology, 23: 265-298.

Gauld I. D., 1991. The Ichneumonidae of Costa Rica, 1. Memoirs of the American Entomological Institute, 47: 1-589.

Gupta V. K., 1969. Taxonomic identity of Eugalta Cameron and Pseudeugalta 
Ashmead (Hymenoptera: Ichneumonidae). Oriental Insects, 3: 193-196.

Gupta V. K., 1980. A revision of the tribe Poemeniini in the oriental region (Hymenoptera: Ichneumonidae). Oriental Insects, 14: 73-130.

Gupta V. K., 1985. A review of the tribe Neoxoridini of world (Hymenoptera: Ichneumonidae: Pimplinae). Oriental Insects, 19: 323-329.

Kriechbaumer J., 1899. Ichneumonologica varia. Contin. Entomologische Nachrichten., 25: 295-303.

Morley C., 1915. Notes and synonymy of Hymenoptera in the collection of the British Museum II. Ann. Mag. Nat. Hist., 8: 331341.

Pham Thi Nhi, Khuat Dang Long, 2016. A checklist of the farmily Ichneumoidae
(Hymenoptera: Ichneumonidae) from Vietnam. Tap chi Sinh hoc, 38(4): 411-442. DOI: $10.15625 / 0866-7160 / \mathrm{v} 38 \mathrm{n} 4.8883$.

Sheng M. L., Sun S. P., 2010. Parasitic Ichneumonids on Woodborers in China (Hymenoptera: Ichneumonidae). Beijing, China: Science Press.

Townes H. K., 1969. The genera of Ichneumonidae, part 1. Ephialtinae to Agriotypinae. Memoirs of the American Entomological Institute, 11: 1-300.

Wang S. F., Gupta V. K., 1995. Studies on the tribe Neoxoridini from China (Hymenoptera: Ichneumonidae: Pimplinae). Oriental Insects, 29: 175-184.

Yu D. S., van Achterberg C., Horstmann K., 2012. Taxapad 2012, Ichneumonoidea 2011. Database on flash-drive. In, Ottawa, Ontario, Canada. 